\title{
Análise de Pós-Ocupação em Acessibilidade para Deficientes Visuais e/ou com Baixa Visão no Centro de Convivência, em Passo Fundo, RS
}

\author{
Post-occupation analysis on Acessibility for the visually impaired and/or low vision \\ people at the Center of Convenience, in Passo Fundo, RS
}

Análisis de Post-Ocupación en Accesibilidad para Deficientes visuales y / o con Baja Visión en el Centro de Convivencia, en Passo Fundo, RS

Sidnei Matana Júnior Arquiteto e Urbanista, Especialista em Design e Interiores, UPF, Brasil sidneimatana@gmail.com

Paula Signor do Nascimento Arquiteta e Urbanista, Especialista em Design e Interiores, UPF, Brasil arqpaulanascimento@gmail.com

Mirian Carasek Professora Mestre Arquiteta e Urbanista, UPF, Brasil miriancarasek@upf.br 


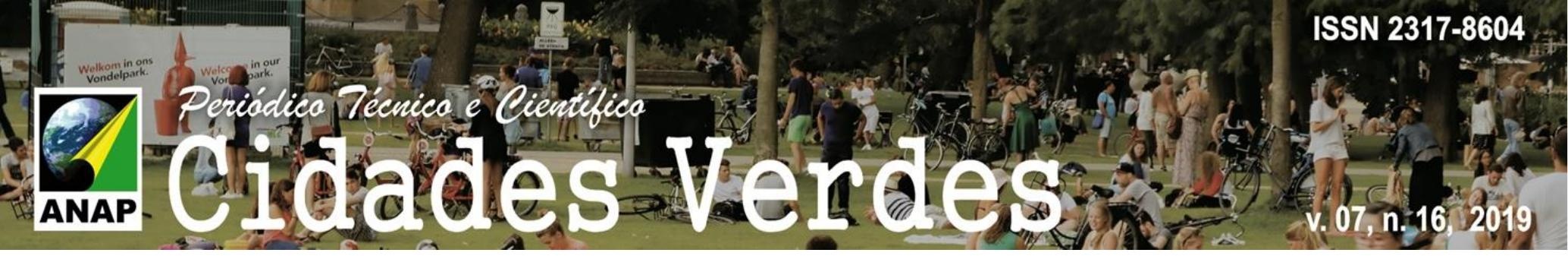

RESUMO

Objetivo: Analisar as condições de acessibilidade do Centro de Convivência da Universidade de Passo Fundo, com foco na acessibilidade para pessoas com deficiência visual ou baixa visão. Método: A análise pós-ocupação foi elaborada a partir da visita in loco da edificação para verificação de acessibilidade, com base nas exigências da ABNT NBR 9050/2015 - Acessibilidade a edificações, mobiliário, espaços e equipamentos urbanos. A coleta de dados, ilustrações e levantamento fotográfico foram realizados pelos pesquisadores. Resultados: Conforme vistoria in loco, determinados pontos pertinentes à norma foram atendidos, sendo que possíveis adequações podem melhorar as condições de acessibilidade. Conclusão: Em relação às pessoas com deficiência visual ou baixa visão, a edificação apresenta condições satisfatórias de acessibilidade, cabendo apenas algumas melhorias.

PALAVRAS-CHAVE: Análise pós ocupação. Acessibilidade. NBR 9050/2015.

\section{ABSTRACT}

Objective: To analyze the accessibility conditions of the Convenience Center, focusing on accessibility for people with visual impairment or low vision. Method: The post-occupation analysis was elaborated from the on-site visit of the building to verify accessibility, based on the requirements of ABNT NBR 9050/2015 - Accessibility to buildings, furniture, spaces and urban equipment. The data collection, illustrations and photographic survey were made by the researchers. Results: According to the on-site survey, certain points pertinent to the standard were met, and possible adjustments may improve the accessibility conditions. Conclusion: In relation to people with visual impairment or low vision, the building has satisfactory accessibility conditions, with only a few modifications.

Keywords: Post-occupation analysis. Acessibility. NBR 9050/2015

\section{RESUMEN}

Objetivo: Analizar las condiciones de accessibilidad del Centro de Convivencia, com foco en la accessibilidad para personas com deficiencia visual o baja visión. Método: El análisis post-ocupación fue elaborado a partir de la visita in situ de la edificación para verificación de accesibilidad, con base en las exigencias de la ABNT NBR 9050/2015 Accesibilidad a edificaciones, mobiliario, espacios y equipamientos urbanos. La recolección de datos, ilustraciones y levantamiento fotográfico fueron realizados por los investigadores. Resultados: Conforme a la inspección en el local, determinados puntos pertinentes a la norma fueron atendidos, siendo que posibles adecuaciones pueden mejorar las condiciones de accesibilidad. Conclusión: En relación a las personas con deficiencia visual o baja visión, la edificación presenta condiciones satisfactorias de accesibilidad, cabiendo sólo algunas modificaciones.

PALAVRAS-CLAVE: Análisis post-ocupación. Accessibilidad. NBR 9050/2015. 


\section{INTRODUÇÃO}

Pode-se entender o habitar como função primordial da arquitetura na concepção dos espaços, o desfrutar desses espaços está relacionado diretamente à autonomia e bem-estar de seus usuários. Sejam atividades de lazer, recreação, descanso e trabalho, os espaços devem oferecer as condições necessárias para quem os habita (MANCUSO, 2016). Dessa forma, diversos estudos foram realizados a fim de avaliar a percepção dos espaços construídos a partir dos seus usuários e sua autonomia durante o uso e ocupação. Diante disso, é crescente a preocupação com projetos que estejam adequados ao design inclusivo, em que crianças, idosos, pessoas com mobilidade reduzida permanente ou transitória e pessoas com algum tipo de necessidade especial tenham conforto, segurança e possam habitar adequadamente os espaços (GURGEL, 2012).

O panorama de envelhecimento da população e aumento do número de pessoas no grupo da terceira idade, a questão da acessibilidade, principalmente quanto à locomoção e utilização segura dos espaços e do mobiliário tem sua importância reforçada (JOURDA, 2012). Conforme a pesquisa a Pesquisa Nacional de Saúde (IBGE, 2013), cerca de 6,2\% dos 200,6 milhões de brasileiros estimados no estudo, possuem algum tipo de deficiência, sendo categorizadas em visual, intelectual, física e auditiva. O foco da pesquisa foi direcionado às pessoas com deficiência visual ou baixa visão, número mais expressivo entre os tipos de deficiências, com proporção de $3,6 \%$, sendo que a região sul apresentou números mais elevados de ocorrência deste tipo de necessidade especial. O Gráfico 1 demonstra a proporção de pessoas com deficiência visual no Brasil, conforme a Pesquisa Nacional de Saúde, - PNS, de 2013 (IBGE, 2013).

Gráfico 1: Proporção de pessoas com deficiência visual, na população total, com indicação do intervalo de confiança de $95 \%$, segundo as grandes regiões - 2013

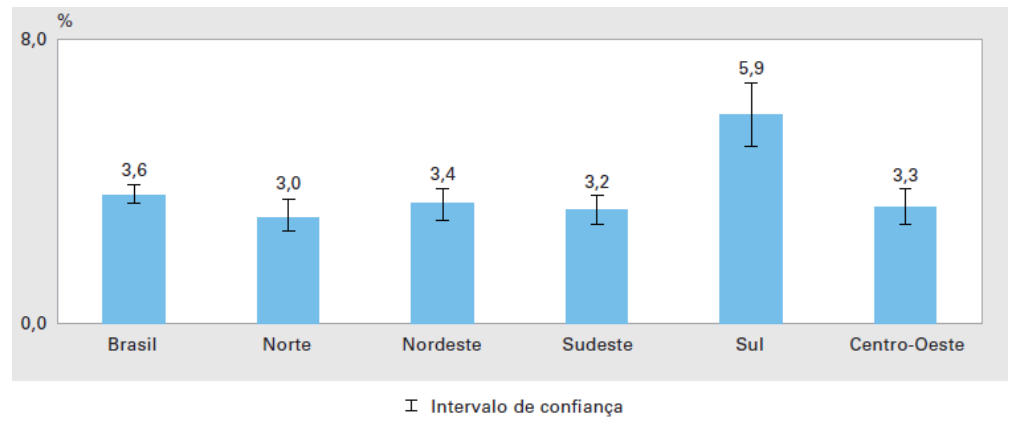

Fonte: IBGE (2013). Disponível em: ftp://ftp.ibge.gov.br/PNS/2013/pns2013.pdf

Cabe salientar, que a partir dos dados da PNS (IBGE, 2013), também é possível identificar que dentre a população que possui deficiência visual, o maior percentual é de pessoas que adquiriam a deficiência através de acidentes ou doenças, em relação às pessoas que já nasceram com a deficiência. O Gráfico 2, apresenta as proporções entre os nascidos e os que adquiriram alguma deficiência visual. 
projetos posteriores (ORNSTEIN E VILLA, 2016). Os procedimentos de pesquisa de APO são constituídos por levantamentos de dados in loco, registros fotográficos, entrevistas e aplicação de questionários, variando conforme o objetivo e tipo de avaliação do estudo, permitindo um processo de análise crítica projetual (VILLA, SARAMAGO e ARAÚJO, 2018). A Avaliação Pósocupação, tal qual instrumento de avaliação, teve seus primeiros ensaios realizados ainda na década de 1980, sendo maturada e consolidada nos anos seguintes, no que tange ao ensino, constituindo uma área temática de pesquisa relevante. É possível compreender a APO como um instrumento de ruptura do sistema convencional de projeto e execução, com etapas sequenciadas, estabelecendo um contraponto, ao realimentar as fases anteriores com dados referentes a utilização, favorecendo melhorias contínuas dos espaços. (ORNSTEIN, 2017).

O objetivo do estudo foi verificar as condições de acessibilidade para deficientes visuais ou com baixa visão, no Centro de Convivência da Universidade, em Passo Fundo, através de análise técnica, bem como elaborar sugestões de melhorias a serem implantadas e estabelecer a primeira etapa de pesquisa a ser complementada através da análise dos usuários.

\section{METODOLOGIA}

A avaliação pós-ocupação pode ocorrer sobre diferentes enfoques, como avaliação funcional, econômico-financeira, ambiental, técnico-construtiva, estética e também sociológica (VILLA, SARAMAGO E GARCIA, 2016). Este estudo trata de uma pesquisa de campo, com levantamento realizado in loco pelos autores, caracterizado por duas linhas de análise. A análise técnica, realizada pelos autores, a fim de analisar a edificação quanto aos aspectos relativos às normas de acessibilidade e possíveis intervenções e melhorias, com elaboração de mapas e levantamento fotográfico, sendo objeto desta primeira etapa. A análise através dos usuários, a ser realizada através de questionário semiestruturado, com dados qualitativos e quantitativos. Antes de analisar as condições de ocupação da edificação em relação à acessibilidade, é necessário esclarecer os principais conceitos, definidos pela Norma ABNT NBR 9050/2015 Acessibilidade a edificações, mobiliário, espaços e equipamentos urbanos. (ABNT, 2015)

\footnotetext{
Acessibilidade: possibilidade e condição de alcance, percepção e entendimento para utilização, com segurança e autonomia, de espaços, mobiliários, equipamentos urbanos, edificações, transportes, informação e comunicação, inclusive seus sistemas e tecnologias, bem como outros serviços e instalações abertos ao público, de uso público ou privado de uso coletivo, tanto na zona urbana como na rural, por pessoa com deficiência ou mobilidade reduzida (ABNT, p.2, 2015).

Desenho universal: concepção de produtos, ambientes, programas e serviços a serem utilizados por todas as pessoas, sem necessidade de adaptação ou projeto específico, incluindo os recursos de tecnologia assistiva (ABNT, p.4, 2015).

Piso tátil: piso caracterizado por textura e cor contrastantes em relação ao piso adjacente, destinado a constituir alerta ou linha-guia, servindo de orientação, principalmente, às pessoas com deficiência visual ou baixa visão. São de dois tipos: piso tátil de alerta e piso tátil direcional (ABNT, p.5, 2015).
}

Sendo assim, as estratégias e dispositivos relacionados a acessibilidade devem visar a autonomia dos usuários, seja em espaços internos ou externos, permitindo a usabilidade dos espaços. Os dados levantados nesta primeira etapa de estudo se referem aos aspectos 
técnicos e qualitativos, tais como a implantação de piso podotátil, rotas de acesso, mapa tátil e outros sistemas que auxiliem a utilização do espaço pelos usuários portadores de deficiência visual ou baixa visão, além da identificação das barreiras e obstáculos encontrados.

O Estatuto da Pessoa com Deficiência (BRASIL, 2015) define o termo barreiras conforme segue:

Barreiras: qualquer entrave ou obstáculo que limite ou impeça a plena participação social da pessoa, bem como o gozo, a fruição e o exercício de seus direitos, à acessibilidade, à liberdade de movimento e de expressão, à comunicação, ao acesso à informação, à compreensão, à circulação com segurança, dentre outros [...] (Brasil, p. 3, 2015).

Foram identificadas e analisadas as barreiras classificadas no Estatuto da Pessoa com Deficiência, as quais são: Barreiras Arquitetônicas; Barreiras Urbanísticas; Barreiras nos Transportes; Barreiras nas comunicações e na informação; Barreiras Atitutinais e Barreiras tecnológicas. Após o levantamento, foram elaboradas propostas iniciais para melhoria das condições de acessibilidade de deficientes visuais ou com baixa visão no, através de mapas de diagnóstico, que servirão como referência também para futuras alterações.

O edifício do Centro de Convivência da Universidade de Passo Fundo (Figura 1), teve a construção iniciada em 2007 e foi inaugurado em 2009. Localizado no Campus, possui praça de alimentação, restaurantes, terminais de caixa eletrônico, lojas e sanitários. Apenas o térreo será analisado, pois o segundo pavimento é destinado galeria de serviços da parte técnica dos restaurantes.

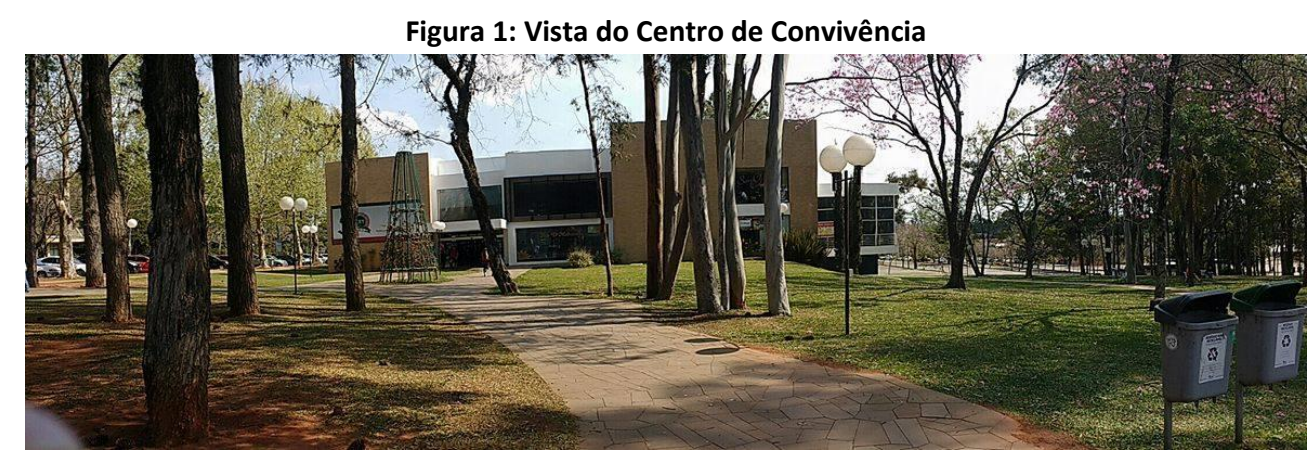

Fonte: Os autores, 2017.

\section{RESULTADOS}

A análise técnica realizada pelos pesquisadores foi constituída pelo levantamento acerca das barreiras encontradas em relação à acessibilidade de pessoas com deficiência visual ou baixa visão no edifício do Centro de Convivência.

a) Barreiras Urbanísticas: Há descontinuidade do piso podo-tátil no campus, sendo necessário implantar rotas em todos os passeios. Há trechos onde o usuário pode acabar até mesmo não conseguindo acessar o edifício por determinadas rotas, também foi constatada a falta de sinalização no campus e nas paradas de ônibus, fato que poderia ser minimizado com a implantação de mais mapas táteis não somente dentro dos edifícios, mas também nas áreas externas, principalmente em paradas de ônibus e outros pontos estratégicos, para que o 


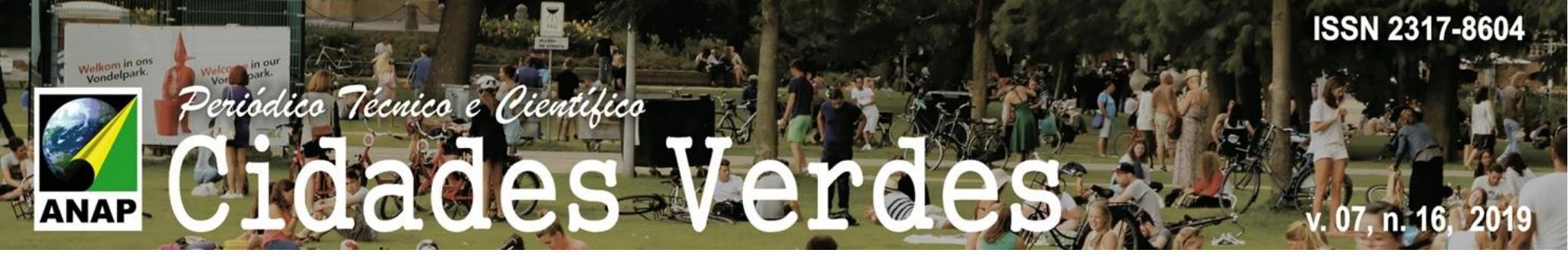

deficiente visual possa se localizar dentro da Universidade e locomover-se para onde deseja. Cabe salientar que o processo de implantação do piso podo tátil não se encontra concluído, devido a extensão do campus, porém, no atual momento, não é possível a autonomia dos usuários deficientes visuais.

b) Barreiras Arquitetônicas: banheiros não adequados para deficientes visuais (Figura 2), uma vez que o piso tátil leva ao espaço, porém não há orientação dentro do espaço. 0 piso podotátil está instalado na parte interna, permitindo acesso as lojas, praça de alimentação, terminais bancários e demais espaços, estabelecendo uma rota.

Figura 2: Banheiro masculino do Centro de Convivência não acessível

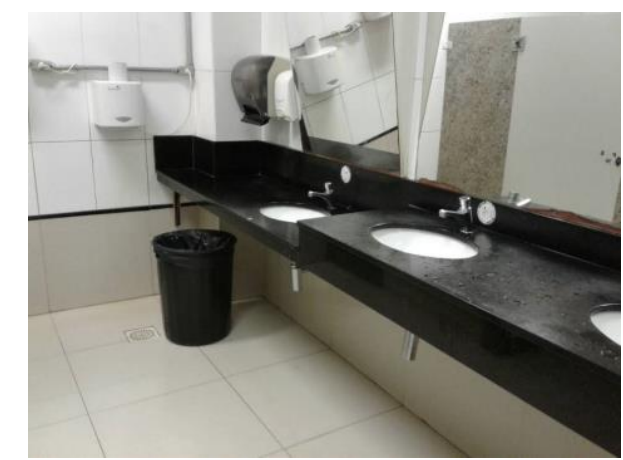

Fonte: Os autores, 2017.

c) Barreiras nas comunicações e informações: ausência de especificação de atividades nos mapas táteis (Figura 3), que podem apresentar mais informações, relativas às atividades oferecidas no Centro de Convivência, além da utilização de cardápios em linguagem Braile e outras estratégias a serem adotadas para que o deficiente identifique os produtos disponíveis. 


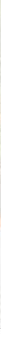

Figura 3: Mapa tátil existente no Centro de Convivência.

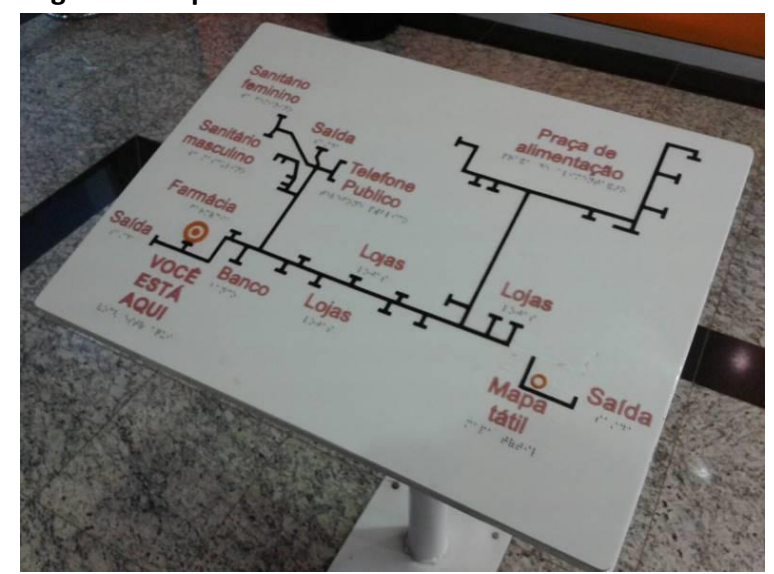

Fonte: Os autores, 2017.

d) Barreiras atitudinais: mesas e cadeiras dispostas no meio do corredor de acesso. Estas mesas podem constituir uma barreira, mesmo que afastadas da rota acessível, a área poderia estar identificada nos mapas táteis, como se pode ver na figura 4.

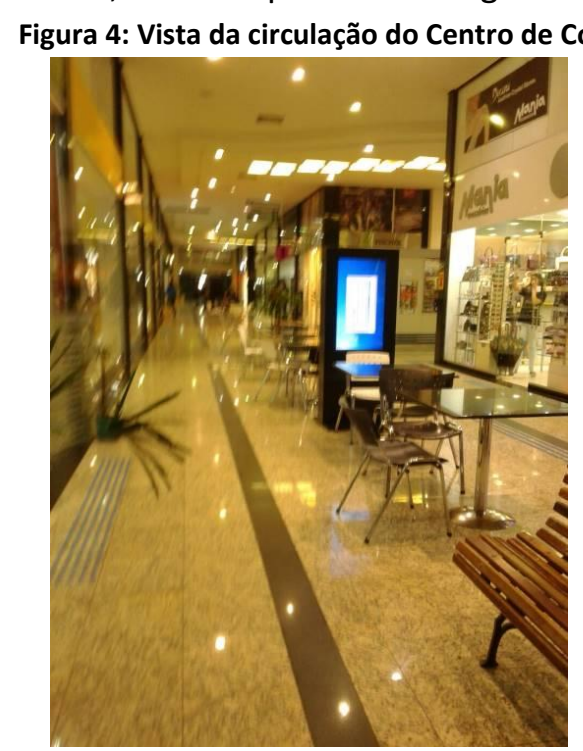

Fonte: Os autores, 2017.

e) Barreira nos transportes: pouca sinalização nas vias de acesso, seria desejável, principalmente nos horários de grande fluxo, que houvesse semáforos com avisos sonoros para que os deficientes visuais conseguissem acessar o local com autonomia (Figuras 5 e 6). Além disso, algumas paradas de ônibus carecem de sinalização tátil. 

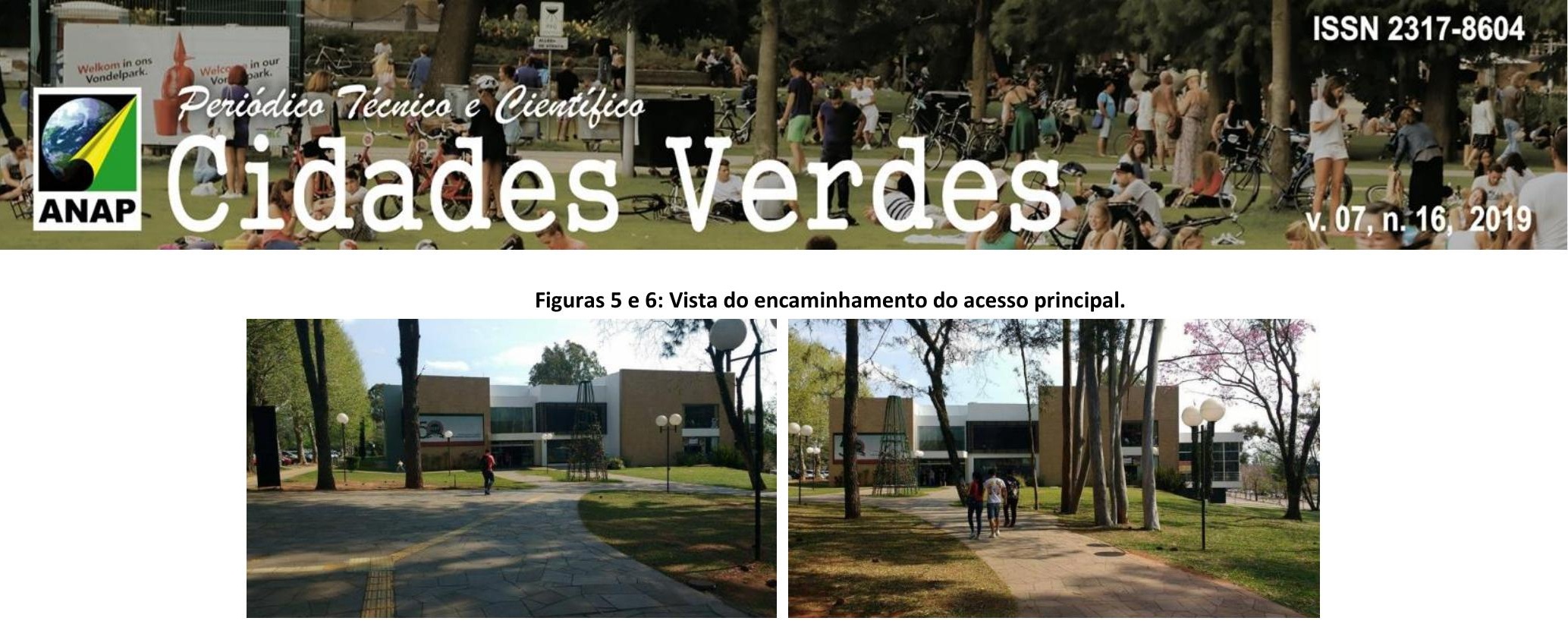

Fonte: Os autores, 2017.

f) Barreiras tecnológicas: há a necessidade de instalação de avisos sonoros. Tal instalação possibilitaria alertar para a existência de barreiras ou situações de emergência, além de servir para informações e para auxiliar a objetivar melhor as atividades lá existentes.

Outro ponto analisado na vistoria in loco foram os aspectos dimensionais do piso podotátil, de acordo com a NBR 9050 (ABNT, 2015) e com a NBR 16537 - Acessibilidade - Sinalização Tátil no piso - Diretrizes para elaboração de projetos e instalação (ABNT, 2016). Nas calçadas de basalto externas, foram utilizados pisos podotátil de bloco de concreto, de $25 \times 25 \mathrm{~cm}$, pintados na cor amarela. O contraste de cores está conforme o recomendado pela norma, bem como as dimensões de cada bloco.

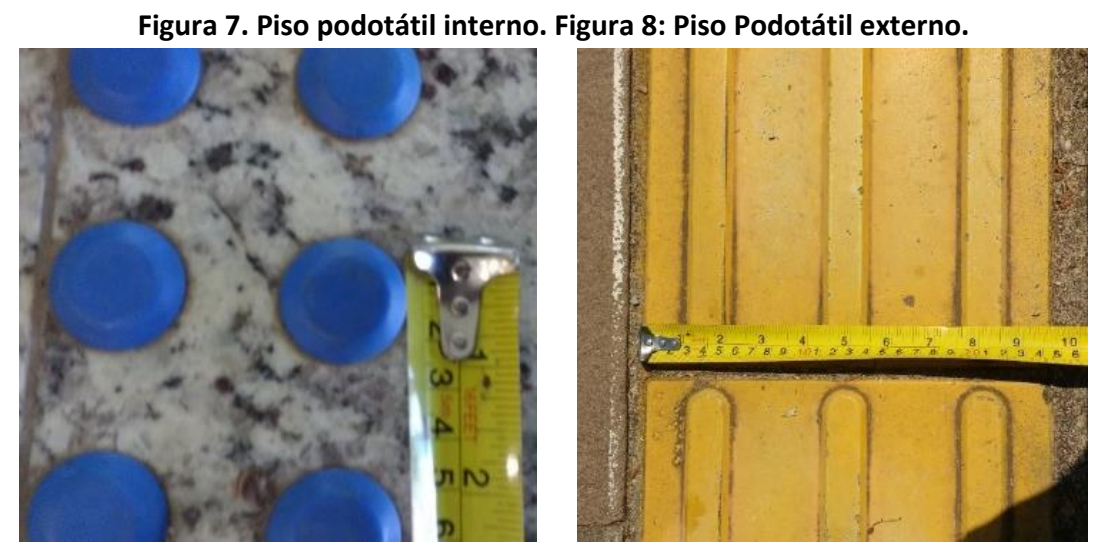

Fonte: Os autores, 2017

Internamente foram utilizados relevos táteis emborrachados, aplicados sobre o piso, de cor azul.

O contraste também está dentro dos padrões, assim como os diâmetros e alturas dos elementos táteis, dentro do recomendado de 25 a 30mm de diâmetro e 4 a $5 \mathrm{~mm}$ de altura. As figuras 7 e 8 demonstram a tipologia de pisos táteis instalados. 
Dessa forma, foi possível constatar em um primeiro momento, que a avaliação pós ocupação constitui uma ferramenta importante para análise crítica da prática projetual, também sendo entendida como uma retroalimentação do processo de projeto. Sendo assim, será imprescindível agregar a análise dos usuários na etapa seguinte deste estudo, uma vez que é possível analisar a edificação através da percepção de seus usuários, suas necessidades diárias, permitindo assim que pontos que não tenham vindo a funcionar possam ser solucionados, adequados e possam constituir um banco de dados para novos projetos.

Cabe salientar que esse processo também contribui para o desenvolvimento do design universal, no qual edificações, equipamentos e objetos possam ser utilizados por todos com autonomia e dignidade.

\section{REFERÊNCIAS}

ASSOCIAÇÃO BRASILEIRA DE NORMAS TÉCNICAS. NBR 9050 - Acessibilidade a edificações, mobiliário, espaços e equipamentos urbanos. Rio de Janeiro. 2015.

ASSOCIAÇÃO BRASILEIRA DE NORMAS TÉCNICAS. 16537 - Acessibilidade - Sinalização tátil no piso Diretrizes para elaboração de projetos e instalação. Rio de Janeiro. 2016.

BRASIL. LEI No 13.146, 6 de julho de 2015. Lei Brasileira de Inclusão da Pessoa com Deficiência (Estatuto da Pessoa com Deficiência). Disponível em: http://www.planalto.gov.br/ccivil_03/_ato20152018/2015/lei//13146.htm. Acesso em 30 de agosto 2017.

Ministério da Educação, Secretaria de Educação Especial. Saberes e práticas da inclusão: desenvolvendo competências para $o$ atendimento às necessidades educacionais especiais de alunos cegos e de alunos com baixa visão. 2a ed. Brasília. 2006. Disponível em: http://portal.mec.gov.br/seesp/arquivos/pdf/alunoscegos.pdf. Acesso em 02 de setembro de 2018.

GURGEL, Mirian. Projetando espaços: guia de arquitetura de interiores para áreas residenciais. São Paulo: Senac 2012.

IBGE. Pesquisa Nacional de Saúde. 2013. Disponível em: https://biblioteca.ibge.gov.br/ visualizacao/livros/liv94522.pdf. Acesso em: 20 ago. 2018.

JOURDA, Françoise-Hélene. Pequeno manual do projeto sustentável. São Paulo: Gustavo Gili, 2012.

MANCUSO, Clarice. Gestão de arquitetura e interiores. São Paulo: Sulina, 2016.

ORNSTEIN, S.E., VILLA, S. Qualidade ambiental na habitação - avaliação pós-ocupação. São Paulo: Oficina de textos, 2016.

ORNSTEIN S. Avaliação Pós-Ocupação (APO) no Brasil, 30 anos: 0 que há de novo? Revista Projetar v.2 n.2 Agosto 2017.

VILLA, S. B.; SARAMAGO, R. C. P.; ARAÚJO, D. C. Avaliação pós-ocupação no ensino de projeto de arquitetura: uma experiência didático-pedagógica na disciplina "Atelier de Projeto integrado V". Gestão e Tecnologia de Projetos, v. 13, n. 1, p. 7-20, 2018. 


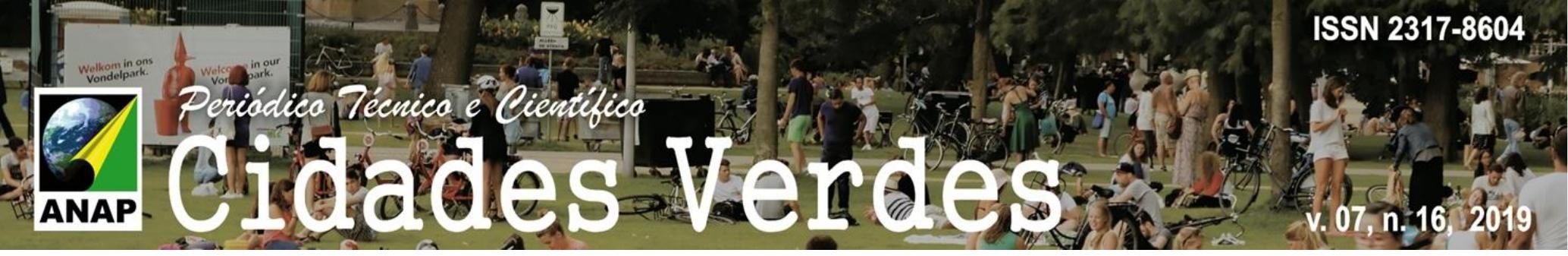

VILLA, S. B.; SARAMAGO, R. C. P.; GARCIA L. C. Desenvolvimento de metodologia de avaliação pósocupação do programa minha casa minha vida: aspectos funcionais, comportamentais e ambientais. Texto para discussão Insituto Nacional de Pesquisa Aplicada, 2016

VILLA, Simone Barbosa; SARAMAGO, Rita de Cássia Pereira; GARCIA, Lucianne Casasanta. Desenvolvimento de metodologia de avaliação pós-ocupação do programa minha casa minha vida: Aspectos funcionais, comportamentais e ambientais. Texto para Discussão, 2016. Disponível em: https://www.econstor.eu/bitstream/10419/177450/1/td_2234.pdf. Acesso em 20 Abr. 2019. 